*Doutor em Direito Empresarial pela UFMG, Mestre e Especialista em Direito; Professor Universitário do Mestrado e da Graduação em Direito da Universidade de Itaúna (UIT), da graduação FUPAC; ex-bolsista CAPES e atual do FUNDEP/UFMG; Coordenador do Projeto Cidade Alteridade em Itaúna; e Advogado.E-mail: eloy. junior@uol.com.br

**Especialista em Direito Público (PUCMINAS). Mestrando em proteção aos direitos fundamentais (UNIVERSIDADE DE ITAUNAUIT). Professor da graduação em Direito (UNIVERSIDADE DE ITAÚNA). Juiz de Direito (TJMG).E-mail: alexmatoso@ ibest.com.br

\section{EFETIVIDAde dos Direitos Fundamentais a Prestações Positivas Sob A Óptica da Teoria de Robert Alexy}

EFFECTIVENESS OF FUNDAMENTAL RIGHTS TO POSITIVE PRESTATIONS FROM THE PERSPECTIVE OF ROBERT ALEXY'S THEORY

\section{Eloy Pereira Lemos Junior* Alex Matoso Silva**}

Como citar: LEMOS JUNIOR, Eloy Pereira; SILVA, Alex Matoso. Efetividade dos direitos fundamentais a prestações positivas sob a óptica da teoria de Robert Alexy. Revista do Direito Público, Londrina, v. 16, n. 1, p. 70-84, abr. 2021. DOI: 10.5433/24157-108104-1.2021v16n1p. 70. ISSN: 1980-511X

Resumo: Vertido no âmbito dos estudos sobre a Teoria do Direito Material Coletivo e tendo como marco teórico as conclusões de Robert Alexy, especialmente aquelas alcançadas na obra Teoria dos Direitos Fundamentais, o propósito deste trabalho é examinar o direito às prestações estatais como instrumento para efetivação dos direitos humanos consignados no texto constitucional. Dar-se-á ênfase para as prestações positivas. Desse modo, a presente pesquisa, do tipo exploratória, que adotará como procedimento a revisão bibliográfica e tendo por método de inferência o dedutivo, buscará validar a hipótese da concretização dos direitos fundamentais por meio da força instrumental da exigência da atuação comissiva estatal para o cumprimento das prestações positivas.

Palavras-chave: Direitos fundamentais. Ações estatais positivas. Prestações fáticas.

Abstract: Produced in the scope of the studies on Collective Material Law Theory and having as a theoretical framework the conclusions of Robert Alexy, especially those found in the Theory of Fundamental Rights, this paper will examine the right to state prestations as a tool for effectiveness of human rights enshrined in the Brazilian Constitution. Emphasis will be placed on positive prestations. Thus, the present exploratory research, which adopts as its procedure bibliographic review and uses as its method of inference deductive reasoning, will seek to validate the hypothesis of the realization of fundamental rights by means of the state's commissive action for the fulfillment of prestations. 
Keywords: Fundamental Rights, Positive State Actions, Factrelated Prestations. 


\section{INTRODUÇÃO}

Os direitos fundamentais, que, em concepção clássica, destinam-se à proteção dos cidadãos contra intervenções estatais que restrinjam liberdades individuais, contemplam duas dimensões de significados opostos, as quais, conquanto pareçam contrapostas, em realidade se complementam.

De um lado, em uma primeira dimensão, sustentam o direito de defesa dos cidadãos, consubstanciando ações negativas - abstenções - do Estado e, de outro lado, em uma segunda dimensão contraposta, obrigam o Estado a agir positivamente, seja mediante ações de fato, para atender direito fundamental negligenciado, seja sob o aspecto normativo, para regular a efetivação de garantias constitucionais.

Com ênfase para as prestações positivas, a presente pesquisa, do tipo exploratória, que adotará como procedimento a revisão bibliográfica e tendo por método de inferência o indutivo, tem como o propósito examinar o direito às prestações estatais como instrumento para efetivação dos direitos humanos consignados no texto constitucional e buscará validar a hipótese da concretização dos direitos fundamentais por meio da força instrumental da exigência da atuação comissiva estatal para o cumprimento das prestações positivas.

Ainda que o tema seja tratado por diversos estudiosos, necessário registrar que o presente artigo será baseado e delimitado nas impressões e conclusões doutrinárias lançadas por Robert Alexy (2008), em sua obra Teoria dos Direitos Fundamentais.

Sob tais limites, o artigo se desenvolverá ao longo de três capítulos e a conclusão.

O primeiro capítulo terá como tema a definição do direito a algo, direito à liberdade - em seu aspecto jurídico - e o direito à competência, tudo sob a óptica de Alexy.

Segue-se a isso o segundo capítulo destinado à apresentação do contraponto entre prestações negativas - abstenções - e prestações positivas - ações - estatal.

Descortina-se, adiante, o terceiro capítulo, voltado às ações positivas, em seu sentido amplo (proteção, organização e procedimento) e em seu sentido restrito (prestações de fato).

Atinge-se a conclusão, que, impossível fugir ao mister, propõe-se a trazer a substância crítica do estudo.

Ainda que essencialmente calcado nas lições de Alexy, por evidente, outros doutrinadores serão chamados como referência no trabalho, em apoio, esclarecimento e até mesmo crítica às posições declaradas pelo autor principal em estudo.

O próprio Robert Alexy em diversas passagens de sua doutrina defende a ideia de que consubstancia questão polêmica a de saber em que medida se deve atribuir aos dispositivos de direito fundamentais a condição de normas que garantam direito a prestações em sentido mais amplo.

Com efeito, ainda conforme assinala Alexy, é intensa e acirrada a discussão sobre os direitos fundamentais sociais - que ensejam as ações positivas estatais, tanto sob o viés normativo, quanto de natureza de prestações fáticas - especialmente no que respeita à assistência social, ao trabalho, à moradia e à educação. 
Toda essa discussão, conforme se verá, decorre da ausência de consenso dos limites do que seja "direitos a prestações", porque possível interpretar essa expressão tanto em sentido estrito - restringindo ao mínimo a responsabilidade do Estado na consecução do bem-estar social - assim quanto emprestar a ela o mais amplo conceito, de modo a abarcar a exigência do máximo de atuação estatal em benefício do bem comum (welfare state).

Qualquer omissão estatal, em tal ou qual sentido interpretativo adotado às ações positivas - restritivo ou ampliativo - sejam prestações fáticas, sejam prestações normativas, imporá a intervenção do Poder Judiciário, mediante provocação do cidadão lesado.

Assim é porque, para implementar e manter uma sociedade mais justa e igualitária, uma vez assegurados os preceitos que garantam a efetividade desses avanços - direitos fundamentais o Estado não pode mais recuá-los, diminuir, romper, cancelar ou os exterminar.

\section{DIREITO A ALGO, LIBERDADE E COMPETÊNCIAS}

Na esteira da lição de Gebran Neto (2004, p. 2, 3), também baseada em Alexy, os direitos fundamentais são compreendidos como “[...] direitos a algo, liberdades e competências", sendo possível dizer, de modo conciso, que "os direitos a algo compreendem ações positivas e negativas por parte do Estado para concretização e respeito dos direitos fundamentais." De se dizer, para efeitos de proteção das pessoas, ou seja, em respeito aos direitos fundamentais, o Estado ora se abstém de agir e, pois, de interferir na seara privada imanente aos cidadãos, ora é chamado a aturar comissivamente nessa mesma seara.

Ter direito a algo, em termos genéricos - sem a crítica científica exigida por Alexy - seria ter direito a uma "pretensão". A fórmula estabelecida por ele para traduzir esse direito assim se expressa: " $a$ " tem, em face de " $b$ ", um direito a "G". Todavia, Alexy prefere a expressão "direito a algo" e explica a opção:

A expressão "direito a algo" pode soar um pouco estranha. Alternativas possíveis seriam "direito (subjetivo)" e "pretensão". Mas direitos (subjetivos) incluem também liberdades e competências. Por isso, essa expressão parece pouco adequada para designar posições que devem ser claramente distinguidas das liberdades e competências. A expressão "pretensão" é mais adequada. O conceito de "direito a algo" compartilha com o conceito de "pretensão" um caráter relacional. Tanto quanto uma pretensão, um direito a algo dirige-se sempre contra alguém, e o objeto é, em ambos os casos, sempre um fazer ou uma abstenção. Contudo, aqui se renunciará à utilização do conceito de pretensão em um sentido técnico. Esse conceito está onerado por inúmeras controvérsias que, no presente contexto, pouco interessam [...]. Se se deixam de lado as controvérsias acerca do conceito de pretensão, as quais dizem respeito, por exemplo, à atualidade, à determinação da parte contrária e3 à exigibilidade judicial, então o direito a algo poderia, sem problemas, ser designado como "pretensão" (ALEXY, 2008, p. 193). 
Alexy assinala que:

Os direitos a algo são relações triádicas entre o titular $(a)$, os destinatários $(b) \mathrm{e}$ o objeto $(G)$ do direito. Só quando existe esta relação entre $a, b$ e $G$, se poderá afirmar que $a$ se encontra em uma posição jurídica caracterizada por ter ele em face de $b$ um direito a $G$ (ALEXY, 2004, p. 182-183, tradução nossa). ${ }^{1}$

O termo liberdade está diuturnamente submetido a uma gama de estudos filosófico, jurídico, social e moral. De todo modo, este capítulo cuidará do conceito de liberdade sob o aspecto jurídico e de acordo com a doutrina de Robert Alexy (2008, p. 218-220).

É por demais espinhoso conceituar o que seja liberdade, pois é termo que, a par de transparecer em si próprio algo que seja de profunda importância e prática, não denota qualquer clareza. Liberdade pode significar o livre arbítrio de agir de um indivíduo, em conformidade com sua própria vontade e sem prejudicar terceiros, assim como, ao mesmo tempo, pode significar um conjunto de ideias liberais, tais os direitos de cada cidadão.

O núcleo do termo liberdade, para Alexy, encontra respaldo na falta de barreiras, entraves, limitações ou embaraços, levando-se em conta o obstáculo e a sua referência.

O componente da liberdade não expressa apenas uma ação individualizada, mas sim uma alternativa; a liberdade pode ser classificada tanto como positiva - uma ação, um agir, um fazer quanto negativa, em que se tem um fazer ou deixar de fazer algo alternativamente.

A liberdade negativa é uma liberdade jurídica ao passo que a liberdade positiva consubstancia na possibilidade de existência de uma única ação.

Para Alexy, uma pessoa é considerada negativamente livre na medida em que a ela não são impostas vedações ou obstáculos nas suas ações, podendo fazer ou deixar de fazer algo, ou seja, são as cognominadas de normas permissivas, em que cada pessoa possui um direito prima facie, direito defronte ao Estado, de que se abstenha de intervir.

O conceito de liberdade jurídica se torna mais amplo porque o seu objeto manifesta-se numa alternativa de ação, ou seja, se expressa acerca da possibilidade de "fazer algo".

O substrato do conceito de liberdade compõe uma relação triádica entre o titular de uma liberdade, assim como de uma não liberdade, um embaraço à liberdade e um objeto da liberdade. Neste posicionamento, Alexy cria uma categoria de "catálogo de liberdade".

O importante é ter ciente que o obstáculo provém de uma norma jurídica garantida, não impedindo o titular de ter a sua liberdade jurídica, de poder fazer ou deixar de fazer.

Neste diapasão, sendo o obstáculo de ordem jurídica garantido pelo direito, há que se examinar se o referido obstáculo é transponível ou não. Em sendo intransponível, não há que se falar em liberdade, em face da existência de uma norma proibitiva. Lado outro, sendo o obstáculo transponível e ainda o elemento ação (fazer ou não fazer) constituir uma alternativa de ação, ter-

1 No original: Los derechos a algo son relaciones triádicas entre el titular $(a)$, los destinatarios $(b)$ y el objeto $(G)$ del derecho. Solo cuando existe esta relación entre $a, b$ y $G$ se encuentra a em uma posicioón jurídica que está caracterizada por tener frente a $b$ um derecho a $G$. 
se-á o direito de liberdade juridicamente garantida. Ao contrário, caso não existente, tem-se a chamada liberdade positiva - "não liberdade".

Alexy (2008, p. 235) assinala que " [...] os direitos a algo e as liberdades representam uma parcela das posições que são chamadas de 'direitos'." Haveria um terceiro grupo constituído pelas posições que o referido autor optou por chamar de "competências".

As competências, conforme assinala Gebran Neto (2004), vem a ser “[...] a capacidade de o indivíduo, por meio de uma ação, vir a modificar a posição jurídica de algo ou de alguém em relação àquela em seu estado natural, pode se dar tanto no direito público como no privado, como o casamento, testamento, ou ingresso no serviço público". Conformam a criação de possibilidade de atos jurídicos e a consequência deles modificarem posições jurídicas. Nesse sentido, arremata Gebran Neto (2004, p. 3):

As competências dos cidadãos que gozam de proteção jusfundamental têm por núcleo central uma proibição dirigida ao legislador de não eliminar ou modificar fundamentalmente determinadas instituições jurídicas de direito privado. A garantia institucional é, pois, em primeira linha, uma proibição dirigida ao legislador de não eliminar determinadas competências do cidadão.

Estabelecidos esses conceitos, importa assinalar que sobre tais direitos e exatamente para a efetivação deles incidem prestações negativas e prestações positivas por parte do estado, conforme se verá adiante.

\section{PRESTAÇÕES ESTATAIS: NEGATIVAS E POSITIVAS - UM CONTRAPONTO}

O exercício dos direitos fundamentais pode ocorrer de duas formas, vale dizer: por meio dos direitos de defesa e por meio dos direitos a prestações. A primeira forma diz respeito às abstenções do Estado frente ao indivíduo, ao passo que na segunda pretende-se uma ação positiva por parte do Estado frente ao indivíduo.

Nesse sentido, tem-se a lição de Maurício Júnior, que, em referência a Alexy, registra:

A existência de direitos sociais prestacionais está normalmente ligada à ideia de um Estado de bem-estar social (welfare state), um sistema no qual o governo fica incumbido da responsabilidade de prover a seguridade social e econômica da população do Estado, através de pensões, benefícios de seguridade social, assistência médica gratuita e outras prestações. Bem-estar não é um conceito quantitativo que pode ser medido em unidades homogêneas, mas sim um conceito relativo, que faz referência à repartição das riquezas sociais. Em outras palavras, o bem-estar não é função da riqueza de um país, mas de sua repartição, devendo ser entendido como "a participação de uma pessoa no desfrute daqueles bens escassos e necessários que compõem o que chamamos de riqueza social". Liga-se o bem-estar, portanto, à ideia de justiça distributiva, já mencionada por Aristóteles como aquela espécie de justiça que se manifesta nas distribuições 
de magistraturas, de dinheiro e de outras coisas que são divididas entre aqueles que têm parte na constituição, e dá lugar, conforme Sanchís, a três espécies de questões: a) que justificação moral pode alegar uma decisão pública acerca da repartição de cargas e recursos, b) que tipo de coisas e necessidades podem ser objeto de uma política de bem-estar, e c) quem ostenta a legitimidade para decidir como se constrói - e a que preço - um bem-estar coletivo (MAURÍCIO JÚNIOR, 2009, p. 33).

Para Alexy (2008), os direitos de defesa, constituem as não-intervenções do Estado frente ao direito individual, que pertencem ao status negativo amplo, ou seja, o direito que impõe ao Estado o dever de não agir, de não violar direitos individuais, como o direito de expressão, inviolabilidade do domicílio, direito de cultos religiosos etc. Direitos de defesa (negativos) surgiram como nascente supletiva de direitos e garantias individuais, que perfilharam a fragilidade humana em face do poder estatal e daquele que o exerce.

Os direitos a ações negativas do Estado, segundo Alexy, podem ser classificados em três grupos: a) direitos a não bloqueio de ações, b) direitos a não afetação das peculiaridades e suas situações e c) direitos a não exclusão de posições jurídicas.

O primeiro grupo - direitos a não-bloqueio de ações - significa a não intervenção do Estado de forma a impor algum empecilho, obstáculo ou embaraço ao titular do direito, não criando complicações ou mesmo tolhendo a ação do titular seja por qualquer meio. Nesta classe enquadram-se, a título de exemplo e de acordo com o ordenamento jurídico brasileiro, o direito de greve e o direito de liberdade de associação sindical, constitucionalmente garantidos (BRASIL, 1988).

O segundo grupo - direitos a não afetação das peculiaridades e suas situações - denota que o Estado não pode comprometer, afetar, contrafazer ou mesmo danificar as características e as situações do titular do direito. Exemplificando, tem-se a situação de não afetação estatal de um direito fundamental de uma pessoa ser saudável ou até uma situação jurídica, como por exemplo, o direito à aposentadoria.

Por fim, o terceiro grupo - direitos a não exclusão de posições jurídicas - reflete na impossibilidade de o Estado alterar ou revogar situações jurídicas constitutivas, como por exemplo a proibição contra a despedida arbitrária, por meio de indenização.

Lado oposto, os direitos a ações positivas exigem do Estado uma persecução de propósitos e finalidades, o que gera muita complicação ao estabelecer em qual padrão/limite os objetivos do Estado podem e devem vincular a direitos subjetivos do indivíduo.

Para Alexy, todas as ações positivas do Estado têm o condão de serem classificadas, quanto à sua interpretação, como de natureza subjetiva e de nível constitucional. Tais direitos podem ser classificados em: a) o grupo dos direitos que exigem do Estado uma prestação, um agir de ordem fática, o que corresponde aos direitos a prestações em sentido estrito e b) o grupo dos que postulam do Estado uma simples assistência ou proteção normativa, correspondendo aos direitos de proteção e aos direitos à participação na organização e no procedimento (prestações em sentido 
amplo).

A viga mestra dos direitos positivos indica uma ação de afirmação do Estado para asseverar a fruição dos direitos fundamentais em conformidade com a Constituição, dentro dos valores e limites estabelecidos. Cumpre também ao Estado a obrigação de prestar o direito de forma contínua, cuja interrupção representa ruptura no próprio direito.

Em resumo, conforme já registrado alhures, conquanto essas duas dimensões de proteção aos direitos fundamentais - ações negativas e ações positivas - pareçam se contrapor, ao, por um lado, impor uma abstenção estatal e, por outro, exigir dele atuação comissiva, em realidade se complementam, porque traduzem forças atuantes a um mesmo propósito.

Inarredável a conclusão de que essas dimensões não se traduzem em forças excludentes; uma não exclui a incidência da outra. Ambas têm o propósito de efetivar os direitos fundamentais.

Com efeito e a tal respeito, Ingo Sarlet sustenta que:

Os direitos fundamentais, como resultado da personalização e positivação constitucional de determinados valores básicos (daí seu conteúdo axiológico), integram, ao lado dos princípios estruturais e organizacionais (a assim denominada parte orgânica ou organizatória da Constituição), a substância propriamente dita, o núcleo substancial, formado pelas decisões fundamentais, da ordem normativa, revelando que mesmo num Estado constitucional democrático se tornam necessárias (necessidade que se faz sentir da forma mais contundente no período que sucedeu a Segunda Grande Guerra) certas vinculações de cunho material para fazer frente aos espectros da ditadura e do totalitarismo (SARLET, 2018, p. 61-62).

Aliás, bem calha a título de conclusão neste tópico o magistério de Gilmar Ferreira Mendes:

Nessa perspectiva, os direitos fundamentais correspondem à exigência de uma ação negativa (em especial, de respeito ao espaço de liberdade do indivíduo) ou positiva de outrem, e, ainda, correspondem a competências - em que não se cogita de exigir comportamento ativo ou omissivo de outrem, mas do poder de modificar-lhe as posições jurídicas.

Conquanto essa seja a perspectiva de maior realce dos direitos fundamentais, ela convive com uma dimensão objetiva - ambas mantendo uma relação de remissão e de complemento recíproco. (MENDES, 2015, p. 167).

\subsection{Ações positivas - sentido amplo (proteção, organização e procedimento) e sentido restrito (prestações de fato)}

Alexy (2008, p. 433-499) divide as ações estatais positivas (direitos a prestações), classificando-as segundo o sentido: a) direitos a prestações em sentido amplo, que abarcaria os direitos à proteção, os direitos à organização e procedimentos; b) direitos à prestação em sentido estrito (direitos fundamentais sociais), que seriam os "direitos do indivíduo, em face do Estado, 
a algo que o indivíduo, se dispusesse de meios financeiros suficientes e se houvesse uma oferta suficiente no mercado, poderia também obter de particulares", estes últimos que, segundo Duarte (2011, p. 61) consubstanciariam as prestações de fato ou ações positivas fáticas. Assim, no sentido amplo, o direito prestacional há de cuidar das perspectivas da proteção e da organização e procedimento e, em sentido restrito, das prestações fáticas.

Os subtítulos seguintes contêm um exame individual de cada qual desses direitos, segundo a classificação ditada por Alexy.

\subsubsection{Direito à Proteção}

O direito à proteção desdobra-se, segundo Azevedo e Silva (2015, p. 59), da dimensão objetiva dos direitos fundamentais, a impor que o "[...] Estado, além de não violar os direitos fundamentais, tem o dever de promover estes direitos e de impedir as ameaças e agressões dos direitos fundamentais por parte de particulares". Aliás, esses autores, citando Sarmento, ressaltam que a teoria dos deveres de proteção foi albergada pela Constituição Federal, ao estabelecer no art. $5^{\circ}$, inciso XLI, que "[...] a lei punirá qualquer discriminação atentatória dos direitos e liberdades fundamentais." (BRASIL 1988).

É de Alexy (2008, p. 450) a assertiva de que como direitos à proteção devem ser “[...] entendidos os direitos do titular de direitos fundamentais em face do Estado a que este o proteja contra intervenções de terceiros.” E complementa:

Direitos a proteção podem ter os mais diferentes objetos. Desde a proteção contra homicídios na forma mais tradicional, até a proteção contra os perigos do uso pacífico da energia nuclear. Não são apenas a vida e a saúde os bens passíveis de serem protegidos, mas tudo aquilo que seja digno de proteção a partir do ponto de vista dos direitos fundamentais: por exemplo, a dignidade, a liberdade, a família e a propriedade. Não menos diversificadas são as possíveis formas de proteção. Elas abarcam, por exemplo, a proteção por meio de normas de direito penal, por meio de normas de responsabilidade civil, por meio de normas de direito processual, por meio de atos administrativos e por meio de ações fáticas (ALEXY, 2008, p. 450).

Interessante registrar aqui a perspicaz observação de Alexy (2008, p. 456) a respeito da posição contraposta entre os "direitos a proteção" e os "direitos de defesa", podendo, alguém colocar em dúvida essa contraposição ao sustentar, como faz Dürig, citado por Alexy, "[...] que também a ação positiva de 'proteção' é ação estatal defensiva e não uma configuração positiva”. Alexy explica estar correta a contraposição:

Nessa afirmação [referindo-se a Dürig] é correto que o direito a proteção diz respeito a uma defesa. Mas com isso esgotam-se os pontos comuns entre o direito de defesa e o direito a proteção. O primeiro é um direito em face do Estado a que ele zele para que terceiros não intervenham. A diferença entre o dever de 
se abster de intervir e o dever de cuidar que terceiros não intervenham é tão fundamental e repleta de consequências que, pelo menos do ponto de vista da dogmática, qualquer relativização nessa diferenciação é vedada. Por isso, a menção do caráter defensivo pode, no máximo, ser compreendida no sentido de uma inserção dos direitos a proteção na tradição liberal. Mas não no sentido de pertencer à classe dos direitos de defesa dirigidos contra o Estado. Não é possível concordar com Dürig quando ele afirma que os direitos a proteção não conduzem a uma configuração positiva. Na medida em que o legislador realiza demarcações entre esferas individuais, exigidas pelos direitos a proteção, ele configura uma parcela decisiva da ordem jurídica e, com isso uma parte essencial da vida social (ALEXY, 2008, p. 456).

Também se poderia duvidar que os direitos a proteção pudessem se enquadrar na categoria de direitos subjetivos. Mas também a respeito disso, Alexy (2008, p. 455) põe uma pá de cal na controvérsia ao asseverar que:

Somente a subjetivização dos deveres de proteção faz justiça ao "sentido original e permanente dos direitos fundamentais" como direitos individuais. Ao contrário do que ocorre com os direitos sociais, ou direitos a prestações em sentido estrito, os direitos a proteção inserem-se inteiramente na compreensão liberal tradicional dos direitos fundamentais (ALEXY, 2008, p. 455).

Tem-se, em síntese, que os direitos à proteção impõem ao Estado uma atuação comissiva em favor dos cidadãos em direção a livrá-los dos riscos - quaisquer que sejam - que uma atividade ou ação de outros cidadãos possam causar àqueles, exemplificativamente, em relação à saúde, propriedade, dignidade, liberdade, trabalho, família, moradia.

\subsubsection{Direito à Organização e Procedimento}

Alberton Júnior (2006) a respeito desse tema específico, também calcado na doutrina de Alexy, afirma que:

[...] a segunda expressão dos direitos a prestação em sentido amplo constitui-se nos direitos à organização e procedimento que podem se apresentar tanto como direitos ao estabelecimento de determinadas normas, quanto direito a uma determinada forma de interpretação e aplicação concreta de normas procedimentais, sendo esses destinados aos Tribunais e aqueles ao Legislador (ALBERTON JÚNIOR, 2006, p. 29).

Com efeito, segundo Alexy (2008, p. 483-484), “[...] à variedade de formas e de conteúdos de organização e de procedimento no âmbito dos direitos fundamentais corresponde uma variedade de possibilidades para sua classificação.” E Alexy, na nessa mesma esteira de pensamento, adverte que uma classificação abrangente, que levasse em conta todas as formas e aspectos do direito à organização e procedimento, somente seria possível com base em uma dogmática detalhada desses 
direitos e conclui:

Sob esse aspecto, e no que diz respeito ao objeto dos direitos, parece ser apropriada uma distinção em quatro grupos: (1) competências de direito privado; (2) procedimentos judiciais e administrativos (procedimentos em sentido estrito; (3) organização em sentido estrito; e (4) formação da vontade estatal (ALEXY, 2008, p. 483-484).

Com referência às competências de direito privado, Alexy (2008, p. 484) esclarece que seriam direitos exigíveis do Estado no sentido da criação de normas “[...] constitutivos para ações de direito privado e, com isso, constitutivas para a fundamentação, a modificação e a eliminação de posições jurídicas de direito privado", podendo versar "[...] tanto à exigência de que essas normas existam quanto à exigência de que tenham um determinado conteúdo.”

Diz-se, pois nesse ponto, da necessidade de existência de normas que possam regular as relações privadas.

Quanto aos procedimentos judiciais e administrativos (em sentido estrito), está-se diante da necessidade de a condução de um procedimento (administrativo ou judicial) sob proteção jurídica de que a decisão final seja isenta de ilegalidade e, em sua essência, seja a tradução da justiça da participação dos envolvidos.

Relativamente à organização em sentido estrito, exige-se que o Estado se estabeleça em formas estruturais de atuação à consecução dos direitos fundamentais, “[...] direitos individuais, dirigidos ao legislador, à existência de normas de organização", “[...] direitos dos indivíduos a que o legislador crie normas de organização que sejam conforme aos direitos fundamentais", na concepção de Alexy (2008, p. 491).

Por fim, quanto à formação da vontade estatal, diz-se dos “"[...] direitos em face do Estado a que este, por meio de legislação ordinária, crie procedimentos que possibilitem uma participação na formação da vontade estatal", conforme Alexy (2008, p. 498). Em essência, essa participação se daria com o direito de votar.

\subsubsection{Direito à Prestação de Fato}

Alexy agiu com precisão cirúrgica ao conceituar os direitos a prestação em sentido estrito como sendo (direitos a prestação de fato):

Direitos do indivíduo, em face do Estado, a algo que o indivíduo, se dispusesse de meios financeiros suficientes e se houve uma oferta suficiente no mercado, poderia também obter de particulares. Quando se fala em direitos fundamentais sociais, como, por exemplo, direitos à assistência à saúde, ao trabalho, à moradia e à educação, quer-se primeiramente fazer menção a direitos a prestação em sentido estrito (ALEXY, 2008, p. 499). 
Quase não há espaço para comentários. Todo modo, segundo o multicitado autor (2008, p. 499), haverá necessidade de diferenciar entre direitos a prestações previstos de forma expressa daqueles direitos atribuídos por meio de interpretação. Isso porque nem todos os direitos sociais prestacionais estarão expressamente consignados no texto constitucional, sendo necessário o exercício interpretativo para ajustar se e quais os direitos fundamentais estariam garantidos a atendimento. Ainda assim, relativamente aos "direitos fundamentais sociais", Alexy enuncia a existência de normas de tipos os mais distintos, que:

A partir de pontos de vista teórico-estruturais, elas podem ser diferenciadas com base em três critérios. Em primeiro lugar, pode-se tratar de normas que garantam direitos subjetivos ou normas que apenas obriguem o Estado de forma objetiva. Em segundo lugar, elas podem ser normas vinculantes ou não-vinculantes neste último sentido seriam elas enunciados programáticos. Uma norma deve ser considerada como "vinculante" se for possível uma análise de sua violação por meio do Tribunal Constitucional Federal. As normas podem, por fim, fundamentar direitos e deveres definitivos ou prima facie, isto é, regras ou princípios (ALEXY, 2008, p. 500).

Alexy lembra que, a par de diferenças estruturais, há outras diferenças:

Especialmente importante é a diferença entre o conteúdo minimalista e um maximalista. O programa minimalista tem como objetivo garantir "ao indivíduo o domínio de um espaço vital e de um status social mínimo", ou seja, aquilo que é chamado de "direitos mínimos" e "pequenos direitos sociais". Já um conteúdo maximalista pode ser percebido quando se fala de uma "realização completa" dos direitos fundamentais, ou quando se caracteriza o direito à educação como "pretensão a uma emancipação intelectual e cultural voltada à individualidade, à autonomia e à plena capacidade político-social". A diversidade acima esboçada dá ensejo à suposição de que o problema dos direitos fundamentais sociais não pode ser resumido a uma questão de tudo-ou-nada. Parece inevitável que diferenciações sejam feitas (ALEXY, 2008, p. 502).

Depois de proceder a uma extensa avaliação de argumentos pró e contra o estabelecimento dos limites dos direitos fundamentais, Alexy (2008, p. 511) propõe um modelo que leve em conta tanto os argumentos a favor quanto os argumentos contrários, sem deixar que a decisão de garantilos ou não, pela importância do problema, fique ao alvedrio da maioria parlamentar, mas imbricada a um sopesamento de princípios, tendo por um lado, especialmente, "o princípio da liberdade fática" e, de outro, "os princípios formais da competência decisória do legislador democraticamente legitimado e o princípio da separação de poderes", sem se olvidar de considerar outros princípios que digam respeito à liberdade jurídica de terceiros e aos demais direitos fundamentais sociais e a interesses coletivos. 


\section{CONCLUSÃO}

Tratou-se neste trabalho sobre direitos fundamentais, tema cujo tratamento, em vista de sua importância, exige correção e legitimidade dos agentes estatais. Conforme mencionado no tópico introdutório, a base deste trabalho foram os estudos, observações e conclusões do jusfilósofo Robert Alexy, especialmente a partir da obra dele Teoria dos Direitos Fundamentais.

Os direitos fundamentais previstos nas Constituições modernas possuem peculiaridades especiais, uma vez que transcendem os alcances e limites nacionais para se tornarem universais, direitos do homem como um todo.

Estes - os direitos fundamentais - são, pois, preceitos estabelecidos no texto constitucional e decorrem diretamente dos direitos humanos, que, assim, tornam-se consagrados no plano interno do direito. São responsáveis por aquiescer os valores da sociedade ao direito, convertendo-os e jurídicos, também apontados como direitos subjetivos dos indivíduos que vinculam e demarcam o poder do Estado e dos particulares, gerando resultados que se estendem por todo o ordenamento jurídico.

São eles que ditam a denominada liberdade jurídica - o fazer ou deixar fazer algo - que, na visão de Alexy, consiste em situações em que o Estado deve abster-se de intervir ou criar algum embaraço, como também situações em que, para efetivação do direito, o Estado deve agir, tem o dever a obrigação de atuar positivamente.

Porque necessário ao entendimento do objeto deste trabalho, delineou-se as dimensões por que os direitos fundamentais se submetem. Contudo, a tônica do estudo cingiu-se à dimensão positiva - ações positivas - em seus sentidos amplo (proteção, organização e procedimento) e restrito (prestações de fato).

Apurou-se, com base em estudos de Alexy, não haver consenso quanto ao conteúdo dos direitos fundamentais e, por consequência disso, restarem indefinidos os limites de atendimento pelo Estado quanto às necessidades dos cidadãos.

Nada obstante, é exatamente no cumprimento dessas obrigações positivas que o Estado, reiteradamente, tem deixado a desejar no acolhimento de demandas da sociedade, as mais diversas. Os cidadãos enfrentam um sentimento de impotência, pois não podem, por sua condição econômico-financeira, suportar os custos de suas necessidades e, apesar de o Estado brasileiro, ter por fundamento a solidariedade social, também não recebem do governo a contrapartida adequada e devida à luz da garantia consignada no texto constitucional.

Os direitos fundamentais têm força de imediata eficácia, razão por que, descuidados pelo Estado, o seu cumprimento pode ser exigido até mesmo via acionamento do Poder Judiciário.

Em relação a um problema de tamanha ordem de importância, é de se concluir, na esteira do entendimento manifestado por Alexy e demonstrado ao longo do desenvolvimento deste trabalho: nem tanto ao mar, nem tanto à terra!

Ainda que, em conclusão geral, esteja efetivamente confirmada a hipótese da concretização dos direitos fundamentais por meio da força instrumental da exigência da atuação positiva estatal 
para o cumprimento das prestações fáticas - via de regra pelo acionamento do Poder Judiciário - não há solução adrede formulada que se aplique a todos os casos indistintamente, de nodo que a resolução do problema, conforme o modelo proposto por Alexy que, deve levar em conta todos os argumentos a favor e contrários à limitação dos direitos fundamentais, baseando-se em sopesamento de princípios.

\section{REFERÊNCIAS}

\section{ALBERTON JÚNIOR, Germano. Controle jurisdicional de direitos fundamentais} prestacionais a partir da proposta de Robert Alexy. 2006. Dissertação (Mestrado em Fundamentos do Direito Positivo) - Universidade do Vale do Itajaí, Itajaí, 2006. Disponível em: https://siaiap39.univali.br/repositorio/handle/repositorio/2047. Acesso em: 10 jan. 2019.

ALEXY, Robert. El concepto y validez del derecho. Traducción de Jorge Seña. 2. ed. Barcelona: Gedisa, 2004.

ALEXY, Robert. Teoria dos direitos fundamentais. Tradução de Virgílio Afonso da Silva da 5. ed. São Paulo: Malheiros, 2008. Versão original alemã.

AZEVEDO, Flávio Alexandre Luciano de; SILVA, Luciana Aboim Machado Gonçalves da. A dimensão objetiva dos direitos fundamentais e sua relevância para a efetivação da cidadania em países periféricos. In: ENCONTRO NACIONAL DO CONPEDI/UFS, 2015, Aracaju, SE. Anais [...]. Florianópolis: CONPEDI, 2015. Tema: Eficácia dos direitos fundamentais e seus reflexos nas relações sociais e empresariais. Disponível em: https://www.conpedi.org.br/publicacoes/ c178h0tg/220z0z30/6p453HGFY7d5FLLD.pdf. Acesso em: 10 jan. 2019.

BRASIL. [Constituição (1988)]. Constituição da República Federativa do Brasil. Brasília, DF: Presidência da República, 1988. Disponível em: http://www.planalto.gov.br/ccivil_03/ constituicao/constituicaocompilado.htm. Acesso em: 10 jan. 2019.

DUARTE, Luciana Gaspar Melquíades. Possibilidades e limites do controle judicial sobre as políticas públicas de saúde: um contributo para a dogmática do direito à saúde. Belo Horizonte: Fórum, 2011.

GEBRAN NETO, João Pedro. Direito a prestações materiais e a efetividade da tutela jurisdicional. 2004. Tese (Doutorado em Direito Constitucional) - Universidade Federal do Paraná, Curitiba, 2004. Disponível em: http://www.stf.jus.br/arquivo/cms/ processoAudienciaPublicaSaude/anexo/Direito_a_prestacoes_materiais_e_a_efetividade_da_ tutela_jurisdicional.pdf. Acesso em: 10 jan. 2019.

MAURÍCIO JÚNIOR, Alceu. A revisão judicial das escolhas orçamentárias: a intervenção judicial em políticas públicas. Belo Horizonte: Fórum, 2009.

MENDES, Gilmar Ferreira. Curso de direito constitucional. 10. ed. São Paulo: Saraiva, 2015.

SARLET, Ingo Wolfgang. A eficácia dos direitos fundamentais: uma teoria geral dos direitos fundamentais na perspectiva constitucional. 13. ed. Porto Alegre: Livraria do Advogado, 2018. 
Como citar: LEMOS JUNIOR, Eloy Pereira; SILVA, Alex Matoso. Efetividade dos direitos fundamentais a prestações positivas sob a óptica da teoria de Robert Alexy. Revista do Direito Público, Londrina, v. 16, n. 1, p. 70-84, abr. 2021. DOI: 10.5433/24157-108104-1.2021v16n1p. 70. ISSN: $1980-511 X$

Recebido em: 22/01/2019

Aprovado em: 11/06/2019 